\title{
Endovascular repair of a dissecting thoracic aortic aneurysm with contained rupture of the false lumen
}
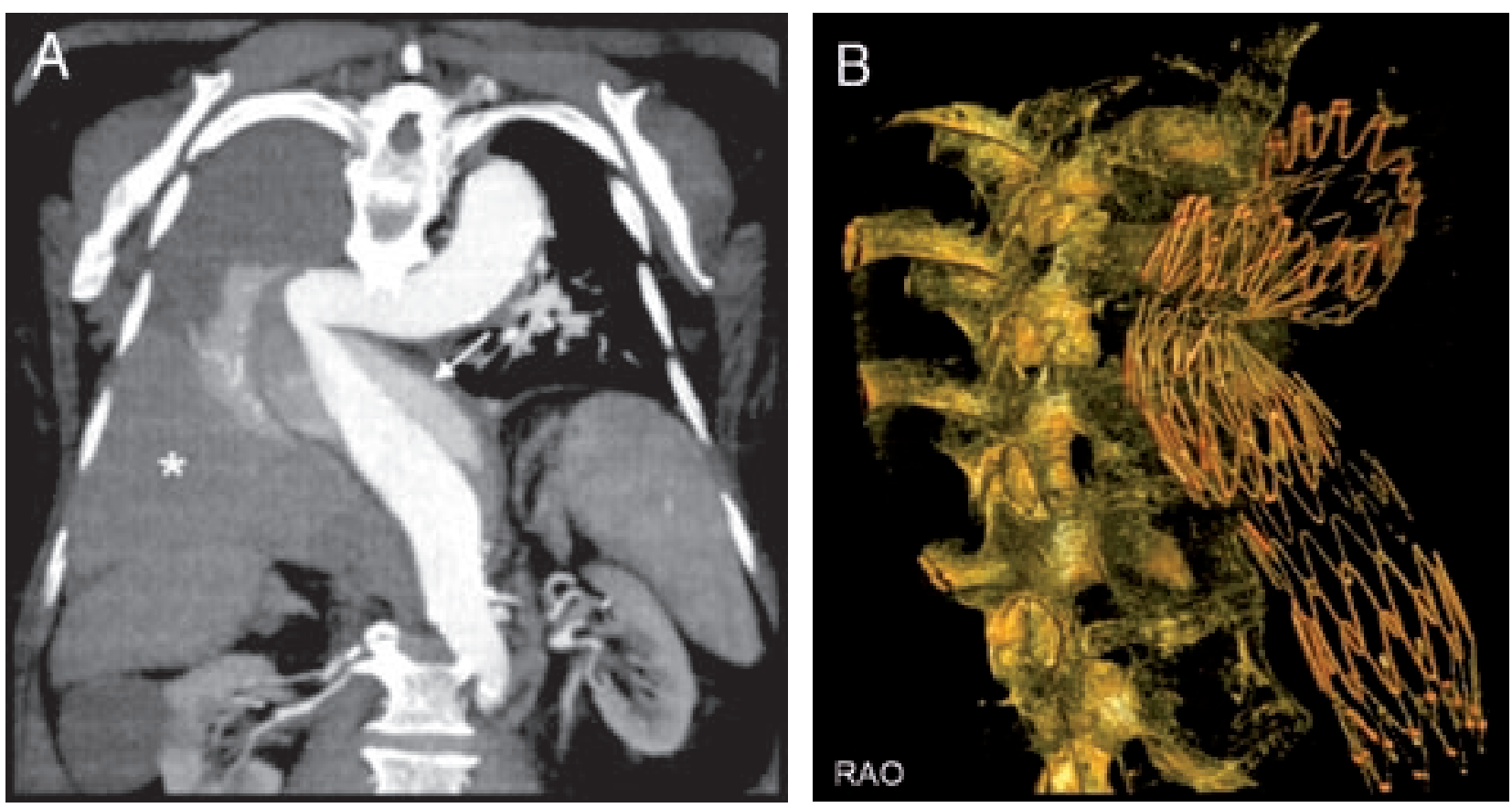

Fig. 1

A 75-year-old man presented with acute onset of back pain and dyspnea. Initial contrast enhanced computed tomography (CT) showed an aneurysm of the distal thoracic aorta. Coronal reconstruction showed atypical type B dissection (Fig. 1A, arrow) distal to vessel kinking, and a right-sided hematothorax (Fig. 1A, asterisk) [1]. Under general anesthesia, the patient underwent endovascular repair of this dissecting aortic aneurysm with contained rupture of its false lumen. Two stents were placed in coaxial technique (Fig. 1B, three-dimensional reconstruction acquired from flat-panel detector-based CT). Concomitantly, medical treatment of NYHA type III cardiac insufficiency and arterial hypertension was initiated. At three months, follow-up CT showed a functioning graft, however, confirmed partial reperfusion of the false lumen around the celiac trunk. With respect to considerable risks and the patient's relatively good condition, it was decided to refrain from reintervention [2].

Thomas Kau, Wolfgang Eicher, Egon Rabitsch, Stefan Celedin, and Klaus Armin Hausegger

\section{References}

1. Olsson C, Thelin S, Stahle E, Ekbom A, Granath F (2006) Thoracic aortic aneurysm and dissection: increasing prevalence and improved outcomes reported in a nationwide population-based study of more than 14,000 cases from 1987 to 2002. Circulation 114: 2611-2618

2. Svensson LG, Kouchoukos NT, Miller DC, et al (2008) Society of Thoracic Surgeons Endovascular Surgery Task Force. Expert consensus document on the treatment of descending thoracic aortic disease using endovascular stent-grafts. Ann Thorac Surg 85: S1-41

Key words: Thoracic aorta, aneurysm, dissection, angiographic CT, stents.

Correspondence: Dr. Thomas Kau, LKH Klagenfurt - Radiologie, St. Veiter Straße 47, 9020 Klagenfurt, Austria, E-mail: t.kau@gmx.at 